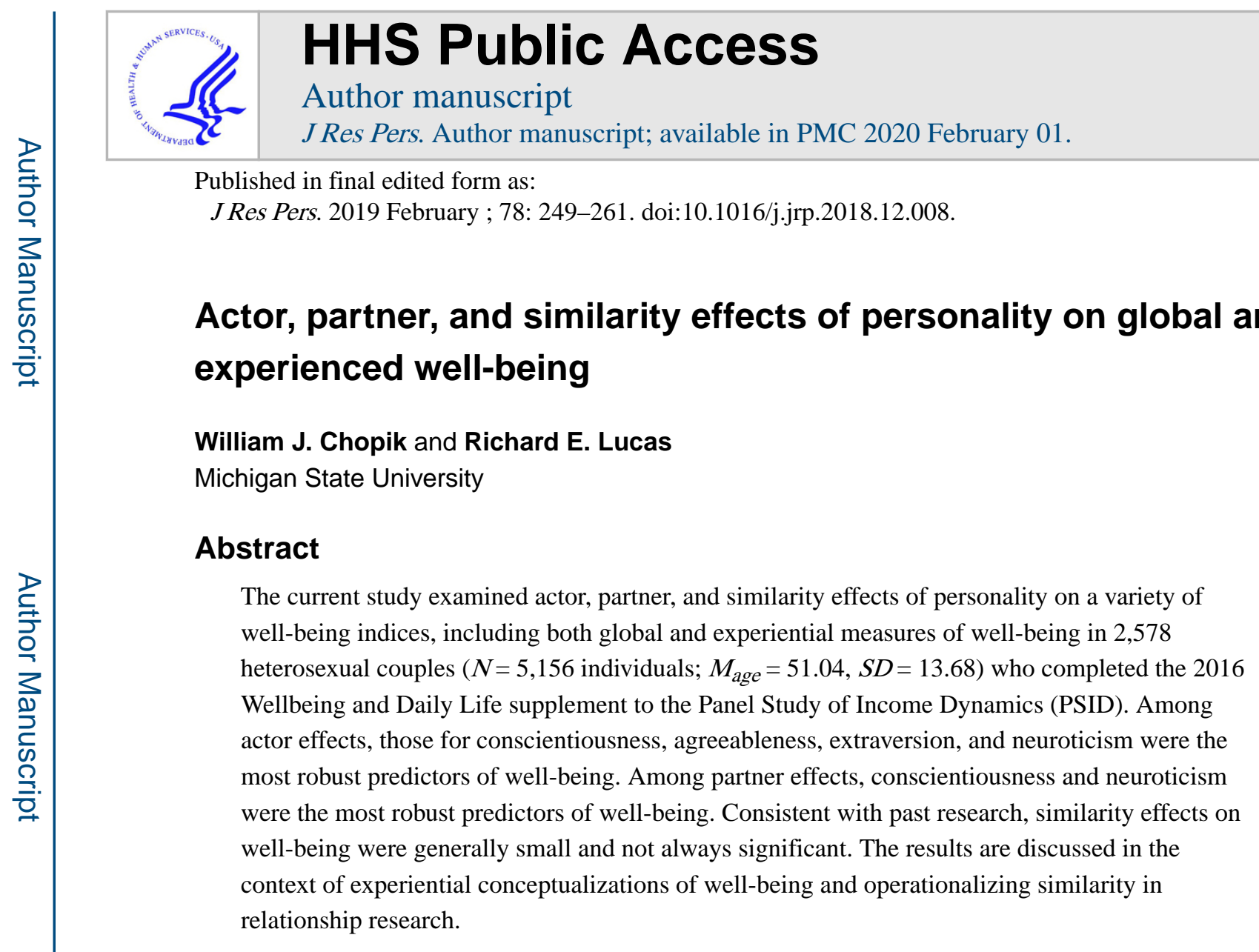

\title{
Keywords
}

subjective well-being; day reconstruction method; dyadic data analysis; Big Five; similarity

\footnotetext{
Correspondence concerning this manuscript should be addressed to William J. Chopik, Department of Psychology, Michigan State University, 316 Physics Rd., East Lansing, Michigan 48824. chopikwi@msu.edu.

${ }^{1}$ In an alternative approach, a recent paper by Weidmann and colleagues (2017) used polynomial multilevel regression techniques to test questions of related to personality similarity within couples. In these analyses, similarity effects are modeled as two-way interactions between actor and partner characteristics (i.e., actor conscientiousness $\times$ partner conscientiousness) while controlling for the linear (i.e., actor conscientiousness, partner conscientiousness) and quadratic (i.e., actor conscientiousness ${ }^{2}$, partner conscientiousness $^{2}$ ) effects of personality. Interactions are often decomposed using response surface analyses (Chopik \& Motyl, 2016; Schönbrodt, 2016). We re-ran each of our models using this approach as well. Similar to what is reported in the main text, the interactions testing similarity were very small and often not significant. Decomposing the few interactions that were significant revealed a multiplicative effect of actor and partner personality, such that individuals report the highest (lowest) well-being when both couple members are higher (lower) in traits. For example, satisfaction with life (measured via the single-item or five item scale) was highest among individuals who were high in conscientiousness and had partners high in conscientiousness relative to the overall sample, although similarity in this context often entails the examination of additional characteristics of a response surface (van Scheppingen, Chopik, Bleidorn, \& Denissen, 2018). We elected to report the absolute similarity effects in the main text as it reproduces previous research more closely and is a within-couple index of similarity compared to an index of linear combinations of personality based on the mean-level of the broader sample (Buyukcan, Campbell, Finkenauer, Karremans, \& Kappen, 2017; Dyrenforth et al., 2010). Copies of these supplementary analyses can be requested from the first author.

${ }^{2}$ Yet another approach to modelling similarity is to compute a profile correlation across all items for each couple and enter this correlation as the index of similarity in predicting well-being outcomes (Dyrenforth et al., 2010). In a series of supplementary analyses, we used both a traditional profile correlation and an index of distinctive similarity (i.e., mean-centering trait scores within each couple member's respective gender)(see Furr, 2008; Humbad, Donnellan, Iacono, McGue, \& Burt, 2013, for an extended discussion). Using both of these indices (in separate models) yielded very similar results to those presented in text and in Footnote \#1; namely, the effects of similarity were very small and often not significant.
} 
The topic of similarity has received considerable attention in relationship research (Byrne, 1961; Byrne \& Nelson, 1965; Finkel, Eastwick, Karney, Reis, \& Sprecher, 2012). Romantic partners tend to be more similar in their personality than what would be expected by chance (Humbad, Donnellan, Iacono, McGue, \& Burt, 2010; McCrae et al., 2008; Watson, Beer, \& McDade-Montez, 2014). This might be explained by selection processes, as people tend to form long-term romantic relationships with people with similar attributes (i.e., assortative mating). In addition to these selection effects, couples tend to become more similar over time, as shared experiences may have joint influences on both partners within a dyad (Mejía \& Gonzalez, 2017; Schimmack \& Lucas, 2010; Watson et al., 2004). Despite similarity being hypothesized to be one of the main reasons why relationships form in the first place, the preponderance of evidence suggests that personality similarity plays a negligible role in how satisfied people are with their lives and their relationships (Dyrenforth, Kashy, Donnellan, \& Lucas, 2010).

Much of the research examining associations between personality similarity and well-being rely on global, evaluative measures of well-being that ask individuals to reflect on the quality of their lives as a whole (e.g., how satisfied are you with your life as a whole?). Recently, however, researchers have developed experiential measures of well-being to assess people's emotional experiences within specific situations and over time. These experiential measures require individuals to provide well-being evaluations either multiple times per day as life is experienced or to retrospectively reconstruct their emotional well-being over the previous day (e.g., Kahneman, Krueger, Schkade, Schwarz, \& Stone, 2004). Experiencebased measures of well-being have been championed as a way to more accurately characterize the emotional experiences of individuals in daily life because in comparison to traditional survey based methods, they rely less on potentially flawed memories or inaccurate aggregations over temporal experiences (Kahneman et al., 2004).

Although the validity and reliability of experiential measures are still being evaluated (Anusic, Lucas, \& Donnellan, 2017; Hudson, Anusic, Lucas, \& Donnellan, in press), it is clear that experiential measures are not completely interchangeable with more traditional global measures. Thus, well-being researchers recommend assessing different conceptualizations of the construct to determine whether similar results are obtained when different measures are used (Diener, Lucas, \& Oishi, 2018). Previous research has examined the role of personality and spousal similarity on global measures of well-being, but it is currently unclear whether the personalities and similarity of couple members exert a stronger influence on experienced well-being than global, evaluative well-being.

The current study examined actor, partner, and similarity effects of personality on global and experiential measures of well-being in a large sample of couples. Previous research has focused primarily on how an individual and their spouse's personalities affect an individual's global evaluation of their well-being (Dyrenforth et al., 2010). In addition to replicating these associations, we extend this research to examine whether comparable (or larger) effects are seen for experiential well-being. Is having a more agreeable partner associated with more positive emotion experienced yesterday? Is being married to someone similar associated with more positive emotion experience yesterday, a more positive life 
evaluation in general, or both? These are just some of the questions we were able to examine in the current study.

\section{Personality and Well-being}

Personality is one of the most consistent predictors of well-being for individuals (DeNeve \& Cooper, 1998; Diener, Suh, Lucas, \& Smith, 1999; Heller, Watson, \& Ilies, 2004). Higher levels of extraversion, agreeableness, conscientiousness, emotional stability, and openness to experience are all associated with higher well-being, albeit moderately so across different measures (e.g., subjective well-being, positive affect; rs ranged from |.02| to |.54|; Steel, Schmidt, \& Shultz, 2008). Likewise, many of these traits also predict relationship satisfaction. Specifically, higher levels of extraversion, agreeableness, conscientiousness, emotional stability, and openness to experience are all associated with higher relationship satisfaction for individuals (Heller et al., 2004).

Although most research on the link between personality and well-being has focused on the association between a person's personality traits and their own well-being, considerable amount of attention has also been dedicated to examining how people's personality traits are associated with the well-being of their romantic partners (Barelds, 2005; Headey, Muffels, \& Wagner, 2010; Orth, 2013; Robins, Caspi, \& Moffitt, 2000). In one meta-analysis, having a partner high in extraversion, agreeableness, conscientiousness, and emotional stability was associated with higher well-being for individuals (Is ranged from |.06| to |.22|; Malouff, Thorsteinsson, Schutte, Bhullar, \& Rooke, 2010). In the largest sample examining actor and partner effects of personality on well-being to date (larger than the aforementioned metaanalysis), Dyrenforth and colleagues (2010) found that partners' conscientiousness, agreeableness, and emotional stability were associated with higher life and relationship satisfaction.

Independent of these actor effects (the effects of an individual's personality on their own well-being) and partner effects (the effects of an individual's personality on their partner's well-being), are similarity effects of personality (the effect of two individual's having similar personalities on an individual's well-being). Similarity is thought to be beneficial in that couples with similar personalities may find it easier to coordinate their thoughts and behaviors and understand one another's intentions (Anderson, Keltner, \& John, 2003). This is one of the reasons why individuals report a preference for romantic partners who are similar to them (Botwin, Buss, \& Shackelford, 1997). The question of how similarity in couples affect relationship satisfaction has received considerable attention but has for many years yielded inconsistent results across studies (Arrindell \& Luteijn, 2000; Gattis, Berns, Simpson, \& Christensen, 2004; Gaunt, 2006; Gonzaga, Campos, \& Bradbury, 2007; Luo \& Klohnen, 2005; Weidmann, Schönbrodt, Ledermann, \& Grob, 2017; Zhou, Wang, Chen, Zhang, \& Zhou, 2017). In the most comprehensive tests of the association between couple personality similarity and well-being (e.g., meta-analyses, studies with large numbers of couples), greater similarity is associated with higher well-being, but many of these effects are negligible in size and often not significant, particularly after the actor and partner effects of personality are controlled for (Barelds, 2005; Dyrenforth et al., 2010; Furler, Gomez, \& Grob, 2013; Montoya, Horton, \& Kirchner, 2008). 
In the current study, we revisited the question of actor, partner, and similarity effects of personality on well-being in a large sample of couples who completed a variety of wellbeing measures. Guided by past research, we hypothesized that higher levels of conscientiousness, agreeableness, and emotional stability in both partners would be associated with higher well-being among individuals. An individual's level of extraversion is typically associated with higher individual well-being, but a partner's level of extraversion is not always associated with higher individual well-being. Thus, we also hypothesized that an individual's extraversion would be associated with higher well-being among individuals. Given the inconsistency from previous studies on the topic, we did not make formal predictions about the effects of similarity on well-being.

\section{Global and Experiential Well-being}

Subjective well-being is an individual's overall appraisal of the positivity in their life and the balance of their affective states (Diener, 1984). There is a great deal of research conceptualizing subjective well-being as a global evaluation of an individual's quality of life - a person's explicit judgment regarding the overall quality of his or her life. Global evaluative well-being is stable over time, responds to changes in life events, and predicts longevity (Anusic \& Schimmack, 2016; Diener \& Chan, 2011; Lucas, 2007; Schimmack \& Oishi, 2005). However, critics suggest that these global evaluative measures of well-being may not accurately capture subjective well-being. According to these critiques, making broad evaluative judgments requires the mental aggregation and averaging of a large amount of information about one's standing in life, which people may find difficult. As a result, individuals may be more susceptible to contextual influences and mental heuristics that might distort global evaluations of well-being (Robinson \& Clore, 2002; Schwarz \& Strack, 1999). Thus, global evaluation measures may be unduly influenced by irrelevant contextual information and thus may not validly capture enduring individual differences in well-being (although see Hudson et al., in press; Yap et al., 2017, for further discussion).

One way of ostensibly avoiding this limitation is to ask people about their emotional states as they are experienced (Kahneman et al., 2004). Early manifestations of such experiential measures of well-being were somewhat intensive and burdensome for participants (i.e., experience sampling methods(ESM)/ecological momentary assessments(EMA); Shiffman, Stone, \& Hufford, 2008). In response to these limitations, Kahneman and colleagues (2004) created the day reconstruction method (DRM), in which people reflect on their previous day and report on their emotional states within a series of specific episodes throughout the day. Specifically, participants are asked to provide a list of episodes that encompass everything they did during the day, to recall how long each episode lasted and what activities it entailed, and to report who they were with and how they felt during each episode. The DRM is considerably less intensive than other experience sampling approaches and can be completed in one sitting. Comparison studies show that there is high correspondence between the DRM and other experience sampling methods (Bylsma, Croon, Vingerhoets, \& Rottenberg, 2011; Dockray et al., 2010). The DRM also has comparable stability and psychometric properties to global evaluative measures (Hudson et al., in press). 
All of the aforementioned studies that examine the association between personality similarity and well-being have relied on global, evaluative measures of well-being. In many ways, one would expect effects from these studies to replicate when alternative, experiential measures of well-being were examined. For instance, at the individual level, personality is related in similar ways to experiential measures of well-being as it is to global evaluative measures, albeit occasionally at lower levels (Hudson et al., in press). This high degree of correspondence is not particularly surprising given the ways in which personality produces stability across daily emotional experiences (Gray, 1987; R. J. Larsen \& Ketelaar, 1991; Watson \& Clark, 1984). There is also evidence that actor and partner personality traits predict relationship dynamics in situ in similar ways that might be reflected in global evaluative measures of well-being (Donnellan, Assad, Robins, \& Conger, 2007; Holland \& Roisman, 2008). Thus, one might expect associations between actor, partner, and similarity effects and well-being outcomes to be comparable across measures.

Yet at the same time, there may be reasons to expect differences. Some accounts of wellbeing stress that our feelings often depend on the things to which we are directing our attention (Kahneman, Krueger, Schkade, Schwarz, \& Stone, 2006; Schwarz \& Strack, 1999). Often when recalling experienced emotions, people draw on more local details of the situation and weigh their influence more heavily (Kahneman et al., 2006; O'Brien, Ellsworth, \& Schwarz, 2012). When people reconstruct their emotions from more finite situations (e.g., yesterday), they may attend to more specific details-who was there, how their interactions made them feel, and the content of interactions they had (or are even currently having) with their romantic partner. In other words, constructing emotional experiences may lead people to rely on details of their current relationship (e.g., their partner's personality), which may augment the role of individual differences in predicting experienced well-being (Chopik, Wardecker, \& Edelstein, 2014). Thus, it could be possible that partner personality and similarity could more strongly predict emotions recalled from finite situations compared to global evaluations of their lives in general. However, this has not been empirically tested.

\section{The Current Study}

The current study revisited associations between actor, partner, and similarity effects of personality on a variety of well-being indices. In a large sample of couples, we extended the question of couple similarity effects to both global evaluative and experienced well-being measures. Based on previous research (Dyrenforth et al., 2010), we expected higher levels of conscientiousness, agreeableness, and emotional stability of both couple members to be associated with more positive well-being (e.g., higher levels of life satisfaction, life standing, global/experienced positive affect, flourishing, relationship satisfaction; lower levels of global/experienced negative affect).

In the current study, we focused on seven different operationalizations of well-being. Many of these well-being indices (e.g., life satisfaction, life standing) can be considered more global, evaluative ratings of well-being and quality of life. These measures seek to quantify an individual's subjective assessment of the quality and standing of their lives as a whole (Pavot, Diener, Colvin, \& Sandvik, 1991). Positive (e.g., enthusiastic, alert) and negative 
affect (e.g., angry nervous) are considered to be the subjective experience of positive or negative feelings within a given time frame (e.g., right now, today, this week, the past 30 days) (Watson, Clark, \& Tellegen, 1988). Flourishing is a concept developed in the subfield of positive psychology that reflects optimal well-being, positive emotions, and social and psychological functioning (Fredrickson, 2001; Keyes, 2002; Seligman \& Csikszentmihalyi, 2000). Because of its broad nature, the most often used flourishing measure is a conglomeration of many positive psychological characteristics (e.g., optimism, purpose in life; Diener et al., 2010). Finally, relationship satisfaction is an evaluation of the well-being of an individual's romantic relationship (e.g., a type of domain specific well-being). Each of these well-being constructs has been shown to be separable from and non-overlapping with one another (Diener et al., 2010; Gustavson, Røysamb, Borren, Torvik, \& Karevold, 2016; Lucas, Diener, \& Suh, 1996), suggesting that they may each show differential associations with personality in the context of romantic relationships. Given the inconsistency from previous studies on the topic, we did not make formal predictions about the differential associations between similarity and global and experiential well-being.

In a series of supplementary analyses, we also examined whether actor, partner, and similarity effects were invariant across gender, age, and relationship length. Examining whether estimates are distinguishable (i.e., moderated) by gender is a recommended analysis when samples are comprised of distinguishable dyads (e.g., heterosexual relationships); occasionally links between actor and partner characteristics and outcomes do vary by gender (e.g., Birditt, Newton, Cranford, \& Ryan, 2016; Kenny, Kashy, \& Cook, 2006). Regarding age, it is unclear whether the associations between personality and well-being are constant across the adult lifespan. Some researchers suggest that personal characteristics might be less influential in old age as the uncontrollable stressors (e.g., health) of late life might suppress any effect that personality has on well-being (Wrosch, Jobin, \& Scheier, 2016). Other research suggests that personal characteristics might be associated with well-being in an invariant way across the adult lifespan (Chopik, Newton, Ryan, Kashdan, \& Jarden, 2018). To our knowledge, the moderating role of age on similarity effects on well-being has not been tested. Finally, partner and similarity effects might ostensibly be largest among couples who have been together longer, as more time allows for the accumulation of benefits (or risk) of certain personality traits for well-being. However, few studies have directly tested this possibility. The few that have tested whether actor, partner, and similarity effects on well-being were moderated by relationship length have found inconsistent results (e.g., Dyrenforth et al., 2010). In the current study, we tested the moderating roles of gender, age, and relationship length on all effects but did not make explicit hypotheses about these analyses.

\section{Method}

\section{Sample and Procedure}

Participants were 2,578 heterosexual couples $\left(N=5,156\right.$ individuals; $M_{a g e}=51.04, S D=$ 13.68) who completed the 2016 Wellbeing and Daily Life supplement to the Panel Study of Income Dynamics (PSID). The PSID is a nationally representative sample of U.S. individuals and their families that have been followed since 1968. To be eligible for the 
Wellbeing and Daily Life supplement, participants needed to be at least 30 years old and have been either a participant or the spouse/partner of a participant from the previous survey wave (2015). Documentation of sampling procedures, a full list of measures, and data are made publicly available through the PSID website. The response rate was $77 \%$ for the supplement. The couples were married on average 21.79 years $(S D=14.99)$. Participants reported their ethnicity as White (71.5\%), Black/African American (19.1\%), Hispanic (4.1\%), Asian (1.7\%), and multi-racial and other ethnicities (3.6\%). Participants had an average of 14.23 years of education $(S D=2.21)$.

The Wellbeing and Daily Life supplement's questionnaires were sent to individual members of the couples (rather than one questionnaire per couple). As a result, some individuals returned questionnaires and their partners did not. In the current study, we only included couples that had complete data for both members. Thus, the current sample differed from the broader sample that completed the Wellbeing and Daily Life supplement but had missing data from one couple member. The majority of these differences were small or negligible. Specifically, compared to couples included in the current analyses, excluded participants were lower in conscientiousness $(d=.10)$, extraversion $(d=.04)$, global positive affect $(d=$. $10)$, experienced positive affect $(d=.09)$, life satisfaction $(d=.40)$, relationship satisfaction $(d=.77)$, and flourishing $(d=.18)$. Excluded participants were also higher in agreeableness ( $d=.09)$, openness $(d=.06)$, global negative affect $(d=.23)$, experienced negative affect ( $d$ $=.17)$, and were slightly older $(d=.09)$ compared to the couples included in the analyses.

Because these are archival analyses, we had no stopping rule and analyzed all available data. Of note, our sample vastly exceeds the suggested minimum of 782 couples required to estimate an effect of $r=.10$ at $p=.05$ (Kenny et al., 2006). The data for this project and documentation of all study variables and procedures are freely available online at https:// psidonline.isr.umich.edu/. The codebook (https://psidonline.isr.umich.edu/WB/ WB2016_codebook.pdf) and user guide (https://psidonline.isr.umich.edu/WB/ WBUserGuide.pdf) for the Wellbeing Supplement are also available at the links provided or via the PSID website.

\section{Measures}

Personality.-Big Five personality traits were assessed with a 15 -item measure developed for the German Socio-Economic Panel Study (Gerlitz \& Schupp, 2005). Conscientiousness ( $a=.62$; "I do a thorough job."), agreeableness ( $a=.61$; "I am considerate and kind to almost everyone."), extraversion ( $a=.66$; "I am outgoing and sociable."), openness to experience ( $a=.70$; "I am original and come up with new ideas."), and neuroticism ( $a=$. 76; "I worry a lot.") were each assessed with three items and participants rated how well each statement described them on a scale ranging from 1(not at all) to 5(a lot). Scale reliabilities are consistent with similar short-form scales of personality (e.g., Donnellan, Oswald, Baird, \& Lucas, 2006).

This 15 -item measure is based on the longer Big Five Inventory (BFI; John \& Srivastava, 1999). The measure's use was validated using data from a large survey of internet respondents $(N=628,640)$ who completed the entire BFI (see Donnellan \& Lucas, 2008; Srivastava, John, Gosling, \& Potter, 2003; for more information). Not only do the 3-item 
subscales correlate highly ( $I \mathrm{~s}>.86)$ with longer versions of the BFI scales, they also correlate with the additional items from the longer BFI that were not included (Is $>.70)$. The utility and appropriateness of truncated measures of personality are discussed extensively elsewhere (Donnellan et al., 2006; Gosling, Rentfrow, \& Swann Jr, 2003; Rammstedt \& John, 2007).

Single-item Life Satisfaction.-A single item indicator of life satisfaction was administered at the beginning of the Wellbeing supplement. The question, "How satisfied with your life as a whole these days?" was answered on a 5-point scale ranging from 1(not at all satisfied) to 5(completely satisfied). Single-item measures of life satisfaction have comparable validity to longer form measures (Cheung \& Lucas, 2014; Lucas \& Donnellan, 2012)

Cantril's Ladder of Life Scale.-The Ladder of Life scale instructs participants to imagine that the top a ladder represents the best possible life for them and the bottom represents the worst possible life for them (Cantril, 1965). Participants indicate which step of the ladder they feel they personally stand at the present time. Responses ranged from 0 (worst possible life) to 10 (best possible life).

Life satisfaction.-Life satisfaction was assessed with the well-established Satisfaction with Life Scale (Diener, Emmons, Larsen, \& Griffin, 1985). A sample item is, "In most ways my life is close to my ideal." Participants rated the extent to which they agreed with each of five items, on a scale ranging from 1 (strongly disagree) to 7 (strongly agree; $a=.90$ ).

Global affect.-Global positive and negative affect was assessed with an instrument asking whether participants felt each of six positive (e.g., full of life) and six negative emotional states (e.g., hopeless) over the past 30 days on a scale ranging from 1(none of the time) to 5(all of the time). Responses were averaged such that higher values corresponded to more positive $(a=.93)$ and negative $(a=.88)$ global affect respectively. Similar measures of global evaluative well-being have been developed for other nationally representative panel studies (Kessler et al., 2002; Mroczek \& Kolarz, 1998).

Experienced affect.-Experienced positive and negative affect was assessed with a variant of the Day Reconstruction Method (Kahneman et al., 2004), in which participants reconstruct their emotional experience throughout the previous day. After reporting what they did and who they were with, participants were asked to report how much of the day they felt each of five positive (e.g., calm) and seven negative emotional states (e.g., frustrated) on a scale ranging from 1(none of the day) to 5(all of the day). Responses were averaged such that higher values corresponded to more positive $(a=.91)$ and negative ( $a=$. 87) experienced affect respectively.

Given the large time and financial commitment required to administer a DRM or experience sampling survey on such a large sample, this abbreviated approach was used by PSID staff to serve as an experiential measure of well-being. In a way, this experiential measure of well-being closely resembles a daily diary-type questionnaire, but involves only reports from a single day rather than many. Proponents of ESM studies note that a strength of these 
studies is that multiple days' worth of assessments yield more stable estimates of well-being. Although more complete ESM/DRM-type measures would be ideal, it is worth noting that the stability of experiential well-being across days is generally high. For instance, Lucas, Freedman, and Carr (2018) found that approximately 50\% of the variance in experiential well-being measures is stable across two days. This suggests that a single day's report of emotional experiences can reasonably represent well-being across multiple days. Further, it is worth noting that additional repeated (intensive sampling) measures of other constructs (e.g., personality) rarely add to incremental validity over-and-above global measures of those constructs (Finnigan \& Vazire, 2017). Given the large amount of variance that single day experiential measures capture and the limited utility of several days of measures (in some contexts), we view this single day measure as at least partially capturing experiential well-being. Nevertheless, we acknowledge this as a limitation of the current study and hope that researchers are able to examine this same question using extended batteries of wellbeing.

Flourishing.-Flourishing was assessed with eight items from a popular flourishing scale (Diener et al., 2010). Participants were asked to rate their agreement with each statement (e.g., "I lead a purposeful and meaningful life.") on a scale ranging from 1(strongly disagree) to 5(strongly agree). Responses were averaged such that high values reflect greater flourishing $(a=.89)$.

Relationship satisfaction.-Relationship satisfaction was assessed with a single item ("How satisfied are you with your marriage or romantic relationship?"; Campbell, Converse, \& Rodgers, 1976) on a scale ranging from 1(not at all satisfied) to 5(completely satisfied).

\section{Analytic Approach}

To account for the interdependence of individuals within dyads, we used multilevel modeling (MLM) procedures recommended for dyadic data analysis (Kenny et al., 2006). MLM estimates both actor effects (associations between a person's personality and his/her own well-being) and partner effects (associations between a person's personality and his/her partner's well-being) while accounting for the statistical non-independence of members in a couple. Following the procedure outlined in Dyrenforth et al. (2010), partner similarity was indexed as the absolute value of the difference between one actor personality trait and one partner personality trait (e.g., |Extraversion ${ }_{\text {Actor }}-$ Extraversion $\left._{\text {Partner }}\right)$. Thus, higher values represent greater dissimilarity between partners. We then took an average of these discrepancy scores across all five traits to yield one measure of couple similarity for the main analyses. Similarity effects were always examined after controlling for the constituent actor and partner effects (Dyrenforth et al., 2010). Supplementary analyses examining whether any similarity effects were attributable to discrepancies in a particular trait (e.g., similarity in conscientiousness might matter more than similarity in openness to experience) were also conducted. ${ }^{12}$

This study was not preregistered

Publisher's Disclaimer: This is a PDF file of an unedited manuscript that has been accepted for publication. As a service to our customers we are providing this early version of the manuscript. The manuscript will undergo copyediting, typesetting, and review of 
Gender was contrast-coded $(-1=$ men, $1=$ women $)$ and predictor variables were grandmean centered. Single-item life satisfaction, Cantril's ladder of life, life satisfaction (the five-item measure), positive/negative global affect, positive/negative experienced affect, flourishing, and relationship satisfaction served as the dependent measures.

\section{Results}

\section{Preliminary Analyses}

Means, standard deviations, and zero-order correlations are presented for men (below the diagonal) and women (above the diagonal) in Table 1. Personality was positively correlated within couples for most traits, except for extraversion (which was negatively correlated within couples), and these correlations were small. Big Five personality traits were also correlated with each other for both men and women (Is range from $|.05|$ to $|.31|$ ). There were many bivariate correlations for actor and partner personality traits and each of the outcomes, all of which were in intuitive directions (e.g., high conscientiousness was associated with higher life satisfaction). However, we postpone discussion of these effects until we consider the models that control for all actor, partner, and similarity effects of personality simultaneously. Each of the well-being outcomes was correlated in expected directions (e.g., negative affect is negatively correlated with life satisfaction, positive affect, flourishing, and relationship satisfaction).

The mean of level of dissimilarity (e.g., |Trait ${ }_{\text {Actor }}-$ Trait $\left._{\text {Partner }} \mid\right)$ was $.84(S D=.36)$, which is the average of dissimilarity in conscientiousness $(M=.67, S D=.57)$, agreeableness $(M$ $=.70, S D=.58)$, extraversion $(M=.99, S D=.78)$, openness to experience $(M=.86, S D=$. $67)$, and neuroticism $(M=.98, S D=.79)$. Dissimilarity was negatively correlated with relationship length, such that couples in longer-term relationships had slightly higher personality similarity $(r=-.06, p<.001)$. For trait-specific dissimilarity, couple members in longer relationships were more similar in agreeableness $(r=-.05, p=.001)$, extraversion $(r$ $=-.05, p<.001)$, and neuroticism $(r=-.06, p<.001)$. Couples in long-term relationship were actually more dissimilar in conscientiousness $(r=.04, p=.010)$; relationship length was not significantly related to similarity in openness to experience $(r=-.02, p=.304)$.

\section{Global Evaluative Well-being}

The results from the multi-level models predicting global evaluative well-being from actor, partner, and similarity personality effects can be seen in Supplementary Tables 1 (for singleitem life satisfaction), 2 (for Cantril's ladder of life), 3 (for life satisfaction), 4 (for global positive affect) and 5 (for global negative affect). We reproduce the range of effect sizes in the text below (see Table 2 for a summary list of effect sizes and significance).

The findings for single-item life satisfaction, Cantril's life ladder, and life satisfaction were nearly identical. With respect to actor effects across the three indices, being higher in conscientiousness, agreeableness, and extraversion were all associated with higher wellbeing. Higher levels of neuroticism were associated with lower well-being. Actor effects

the resulting proof before it is published in its final citable form. Please note that during the production process errors may be discovered which could affect the content, and all legal disclaimers that apply to the journal pertain. 
ranged in size from $|.06|$ to $|.42|$. For partner effects across the three indices, higher levels of conscientiousness and lower levels of neuroticism predicted higher levels of well-being. Partner effects ranged in size from |.04| to |.13|. Across the three indices, couples with similar levels of personality reported higher well-being (ranging from -.04 to -.08 ).

For global positive affect, with respect to actor effects, higher levels of conscientiousness, agreeableness, extraversion, and openness to experience were each uniquely associated with higher levels of global positive affect. Higher levels of actor neuroticism were associated with lower levels of global positive affect. Actor effects ranged in size from |.03| to |.27|. For partner effects, having a partner low in neuroticism was associated with higher levels of global positive affect (-.05). Couples with similar levels of personality reported higher global positive affect $(-.04)$.

For global negative affect, with respect to actor effects, higher levels of global negative affect. conscientiousness, agreeableness, and extraversion were each associated with lower levels of Higher levels of neuroticism and, surprisingly, openness to experience were associated with higher global negative affect. Actor effects ranged in size from |.03| to |.34|. For partner effects, having a partner higher in conscientiousness (-.03) and lower in neuroticism (.04) were each associated with lower levels of global negative affect. Couple similarity was unrelated to global negative affect.

\section{Experienced Well-being}

The results from the multi-level models predicting experienced well-being from actor, partner, and similarity personality effects can be seen in Supplementary Tables 6 (for experienced positive affect) and 7 (for experienced negative affect).

For experienced positive affect, with respect to actor effects, higher levels of conscientiousness, agreeableness, extraversion, and openness to experience were each associated with higher levels of experienced positive affect. Higher levels of neuroticism were associated with lower levels of experienced positive affect. Actor effects ranged in size from $|.06|$ to $|.29|$. For partner effects, having a partner high in conscientiousness (.02) and low in neuroticism (-.06) were each associated with higher levels of experienced positive affect. Couple similarity was unrelated to experienced positive affect.

For experienced negative affect, with respect to actor effects, higher levels of conscientiousness, agreeableness, and extraversion were each associated with lower levels of experienced negative affect. Higher levels of neuroticism and openness to experience were associated with higher levels of experienced negative affect. Actor effects ranged in size from |.03| to |.27|. With respect to partner effects, having a partner high in conscientiousness and low in neuroticism and openness to experience were each associated with lower levels of experienced negative affect. Partner effects ranged in size from |.02| to |.05|. Couples with similar personalities reported lower levels of experienced negative affect (.02).

\section{Flourishing}

The results from the multi-level model predicting flourishing from actor, partner, and similarity personality effects can be seen in Supplementary Table 8. For actor effects, higher 
levels of conscientiousness, agreeableness, extraversion, and openness to experience were each associated with higher levels of flourishing. Higher levels of neuroticism were associated with less flourishing. Actor effects ranged in size from |.06| to |.15|. For partner effects, having a partner high in conscientiousness (.02) and low in neuroticism (-.04) were each associated with higher levels of flourishing. Couples with similar personalities reported higher levels of flourishing (-.03).

\section{Relationship Satisfaction}

The results from the multi-level model predicting relationship satisfaction from actor, partner, and similarity personality effects can be seen in Supplementary Table 9. For actor effects, higher levels of conscientiousness, agreeableness, and extraversion were each associated with higher levels of relationship satisfaction. Higher levels of neuroticism were associated with lower relationship satisfaction. Actor effects ranged in size from |.04| to |.12|. For partner effects, having a partner high in conscientiousness and agreeableness were each associated with higher levels of relationship satisfaction. Having a partner with higher levels of neuroticism and, surprisingly, higher levels of extraversion were each associated with lower relationship satisfaction for individuals. Partner effects ranged in size from $|.03|$ to $\mid$. 06|. Couples with similar personalities reported higher levels of relationship satisfaction (-. 07).

\section{Summary of Actor, Partner, and Similarity Effects}

Table 2 presents a summary of the significant findings (and direction) for each of the multilevel models.

Statistically significant actor effects were generally small in magnitude, ranging from $|.03|$ to |.42|, rarely exceeding |.10|. Across all indicators of well-being, being high in conscientiousness, agreeableness, and extraversion was associated with higher well-being. Higher levels of neuroticism were associated with lower levels of well-being across all indicators. Openness to experience was associated with higher levels of global and experienced positive affect but also global and experienced negative affect (and flourishing). These unexpected findings may be the result of at least two underlying processes. First, there is evidence that some individuals (especially those high in openness) may experience cooccurring positive and negative affect (Barford \& Smillie, 2016; J. T. Larsen, Coles, \& Jordan, 2017; Scott, Sliwinski, Mogle, \& Almeida, 2014). Second, these findings may be attributable to a suppression effect after actor and partner personality traits were controlled for. Supporting this interpretation is that bivariate associations between openness to experience and negative affect went from negative and occasionally non-significant (see Table 1) to significant and positive. However, future research can replicate this result to see if openness to experience reliably predicts both positive and negative well-being. It is worth noting that other research has also found perplexing associations between actor/partner openness to experience and well-being (Dyrenforth et al., 2010).

Statistically significant partner effects were generally small in magnitude and less than half the magnitude of actor effects, ranging from |.02| to |.13|, rarely exceeding |.05|. Among partner effects, higher levels of conscientiousness and lower levels of neuroticism were most 
consistently associated with higher well-being. The difference in magnitude between actor and partner effects may be attributable to the fact that actor effects can be inflated by shared method variance. The role of method variance is a major consideration when estimating cross-partner effects of personality in dyadic research (Orth, 2013).

For similarity effects, greater similarity was generally associated with more positive and less negative well-being. However, these effects were smaller than actor effects, comparable to partner effects, and were not present for global negative affect and experienced positive affect (although they were in a similar direction). In supplementary analyses, we entered similarity scores for all of the Big Five personality traits (in lieu of the average similarity index in Supplementary Tables 1-9) in a model predicting each well-being outcome. These similarity scores were entered simultaneously while controlling for actor and partner effects of personality (see Supplementary Tables 10-18). These results are summarized in the lower panel of Table 2. Similarity in conscientiousness was most robustly related to well-being; however, the composite (i.e., average) measure of similarity was more predictive of wellbeing than the separate similarity indices.

The findings from the current study align well with those of Dyrenforth et al. (2010) who found small similarity effects (compared to actor and partner effects) of personality. We extended this work by showing that spousal similarity effects are also present for a variety of other well-being measures. It is worth noting that the magnitude of actor, partner, and similarity effects of personality were comparable across both global and experienced wellbeing.

\section{Supplementary Analysis}

Although we entertained a number of possible moderating factors in these Supplementary Analyses, it is worth noting that this section involves running several statistical tests. In our main analyses, for each dependent variable, we modeled actor effects $(n=5)$, partner effects $(n=5)$, a similarity effect $(n=1)$, and age, gender, and relationship length as controls $(n=3)$. In addition to these 14 tests, each moderation model adds an additional 13 tests (for all possible moderation tests for age/gender/relationship status). Although some of these tests are redundant, the number of tests alone in this section is 729 (27 tests/outcome $\times 9$ outcomes $\times$ 3 types of moderation). This leaves open the possibility that a good number of these results may be significant by chance. Thus, we recommend caution in interpreting the veracity of these supplementary results given that many of the significant results (a) would not survive even the most liberal p-value correction and (b) have uncorrected p-values that fall between . 01 and .05, which suggests low evidentiary value (Benjamin et al., 2018).

Gender distinguishability.-One common approach in dyadic analyses is to examine whether actor, partner, and similarity effects are distinguishable (i.e., moderated) by gender. In short, if an effect is distinguishable, a significant test of distinguishability would suggest that an estimate is stronger or weaker among men compared to women. To this end, each of the models was re-run with interaction terms estimated between gender and actor, partner, and similarity effects of personality. The vast majority (103 out of 117 possible effects across the nine models $=88 \%$ ) of actor, partner, and similarity effects were indistinguishable 
by gender. The few exceptions in which gender did moderate the effects can be seen in Table 3. The effects between men and women were quite similar. Having a wife high in extraversion was more predictive of well-being for men. Men's neuroticism was more predictive of lower well-being for both themselves and their wives. There was an overall pattern in which the actor and partner effects of personality on well-being were stronger in men (12 out of 14).

Age moderation.-Because of the wide age range of the sample, we also investigated whether any actor, partner, and similarity effects were moderated by age. Significant moderation by age would suggest that the effects of personality may be stronger or weaker among younger compared to older adults. To this end, each of the models was re-run with interaction terms estimated between actor age and actor, partner, and similarity effects of personality. As with gender, the vast majority ( $86 \%$ ) of actor, partner, and similarity effects were consistent across younger and older adults. Table 4 summarizes the few exceptions to this pattern. Of these few moderation effects, the majority of them were stronger among older adults (12 out of 16). Specifically, being high in agreeableness and having a partner high in conscientiousness were especially beneficial for well-being among older adults. Relationship length was associated with more positive well-being only among older adults. However, the interaction between age and relationship status should be interpreted with caution given the high correlation between the two $(r=.78, p<.001$; i.e., older adults also had the longest relationships). The effects that were stronger for younger adults were often not significant for older adults.

Relationship length moderation.-One obvious question when examining the effects of actor, partner, and similarity effects of personality on well-being is whether these effects are moderated by relationship length. Intuitively, it would make sense that the effects of personality (and similarity) would be stronger among couples who have been together longer and have had more opportunities to influence each other's' well-being. To examine these questions, we conducted one final moderation test similar to the two reported above, but for relationship length. As seen in Table 5, most effects (91\%) were invariant across relationship length. The positive effects of partner conscientiousness on well-being were only present among individuals in long-term relationships. No other consistent patterns were found. The remaining moderation effects with age reproduce the interaction effects found in Table 4 .

\section{Discussion}

The current study examined actor, partner, and similarity effects of personality on global, evaluative well-being and experiential well-being. The findings from the current study align well with past research examining actor and partner effects on global evaluative well-being (Dyrenforth et al., 2010; Malouff et al., 2010). Specifically, higher levels of conscientiousness, agreeableness, and extraversion and lower levels of neuroticism were each associated with higher well-being (Steel et al., 2008). Across all well-being outcomes, actor neuroticism had the largest effect for individual well-being. We did not have any a priori reasons to expect that neuroticism would exert the largest effect on well-being compared to other Big Five traits. However, when examining other studies of both couples and individuals, an individual's level of neuroticism often has the largest association with 
well-being, and this is true across different ways of assessing well-being (e.g., Dyrenforth et al., 2010; Hudson et al., in press; Steel et al., 2008; van Scheppingen et al., 2018). This consistent finding that neuroticism and well-being are so strongly related, relative to the other Big Five traits, is also corroborated by other studies that find the greater emotional reactivity experienced by people high in neuroticism (Bolger \& Schilling, 1991; R. J. Larsen \& Ketelaar, 1991; Suls, Green, \& Hillis, 1998).

Having a partner higher in conscientiousness and lower in neuroticism were each associated with higher well-being (Dyrenforth et al., 2010). Partner agreeableness is often found to be a significant predictor of individual well-being but was not in the present study. The fact that we did not find partner agreeableness to significantly predict well-being could be attributable to how our sample differs from previous samples (e.g., middle aged and older American adults), our measures of personality or well-being, or another reason entirely. It is worth noting that the direction of the partner effects for agreeableness are in an intuitive direction (i.e., having an agreeable partner is associated with higher well-being) but the effects are small and not significant. A practical, albeit less interesting possibility, is that the effects of partner agreeableness on well-being are so small to begin with that they are not significant after fully modeling actor, partner, and similarity effects in other Big Five characteristics. Actor openness to experience surprisingly predicted both positive and negative affect, which is also similar to previous mixed findings with this dimension (Dyrenforth et al., 2010) and/or the aforementioned suppression effect. Effect sizes did not exceed |.42| (for actors) and |.13| (for partners), which is also consistent with previous research. Similarity effects were small across well-being indices, replicating previous work.

\section{Partner and similarity effects of personality on well-being}

We extended research on couple personality similarity to examine its effect on experiential well-being measures. The extent to which individual differences in personality predict global versus experiential well-being is unknown, especially with respect to partner and similarity effects. Some research suggested that personality-well-being associations should be comparable across global and experiential measures (e.g., Hudson et al., in press). We also presented some research suggesting that situational features, like relationship and partner characteristics, might enhance the personality-well-being associations, especially for partner and similarity effects. Prior to the current study, this possibility had not been tested. The results from the current study suggest that actor, partner, and similarity effects of personality on well-being are similar in magnitude across different operationalizations of well-being, whether well-being is reported globally, in specific situations, or reconstructed from memory (Anusic et al., 2017; Donnellan et al., 2007; Hudson et al., in press). Thus, the suggestion that partner or similarity in personality between partners may be more closely related to experiential well-being was not supported. In fact, like other research (Hudson et al., in press), we found a high degree of convergence in the associations between actor personality, partner personality, and partner similarity and well-being across the different operationalizations.

The current study has implications not only for evaluating the differences between global and experiential well-being measures but also for further situating the importance of 
personality similarity in the relationships literature. Although similarity has been a cornerstone of research on romantic attraction and initiation (Byrne, 1961), the results of our study and others further call into question the contribution that similarity has on couple wellbeing. Along with the lack of explanatory power for global well-being measures (Dyrenforth et al., 2010), it also appears that personality similarity might not predict emotional experiences in specific situations either. Importantly, the current report is far from the final word on quantifying the importance of personality similarity in romantic relationships. Instead, we hope that future researchers capitalize on the limitations of the present study to examine (a) how similarity is operationalized, (b) the changes in and functional significance of personality similarity over time, and (c) the mechanisms underlying links between personality and well-being in the context of close relationships. We outline our thoughts on each of these limitations below.

\section{Limitations and Directions for Future Research}

The current study had a number of limitations that can provide the opportunity to further examine the link between actor, partner, and similarity effects of personality on well-being.

Operationalization of similarity.-In the current set of analyses, we modeled similarity as an absolute difference score between couple members, actor-partner interaction terms (see Footnote \#1), and profile correlations (see Footnote \#2). However, there are a number of ways that similarity can be operationalized-difference scores, profile correlations, actorpartner interactions (in the context of polynomial regression), latent constructs (in the context of structural equation modeling), and likely more (Dyrenforth et al., 2010; Furr, 2008; Griffin \& Gonzalez, 1995; Humbad et al., 2013; Luo et al., 2008; Mejía \& Gonzalez, 2017; Rogers, Wood, \& Furr, 2018; Weidmann et al., 2017). Further, these approaches to estimating similarity have been conducted primarily using self-reports of psychological characteristics, which might affect the relative magnitude of actor, partner, and by extension, similarity effects of personality on well-being (Orth, 2013). Although no comprehensive comparison between these methods, nor across informants, has been undertaken, highlighting the utility of each approach can be a useful direction for future research. Regarding the substantive question of the contribution of personality similarity to wellbeing, the preponderance of evidence from papers using different approaches to operationalizing similarity suggests that similarity effects are still often small in magnitude or not significant predictors of well-being (Mejía \& Gonzalez, 2017; van Scheppingen et al., 2018). The consistency across approaches suggests that difference scores may offer a rough approximation of the effects of personality similarity on well-being. Yet other perspectives suggest that similarity in other aspects (e.g., behavior; Youyou, Stillwell, Schwartz, \& Kosinski, 2017) or couples merely perceiving that they are similar (regardless of actual similarity; Tidwell, Eastwick, \& Finkel, 2013) are more important to attraction and wellbeing than personality similarity gleaned from self-report measures. Indexing similarity in behavior and perceived similarity have been modeled using difference score and profile correlation approaches as well. Additional and more formal comparisons of these approaches to indexing similarity should be conducted. 
Cross-sectional nature of the data.-The data from the current study were crosssectional in nature, precluding our ability to measure the prospective effects of personality similarity on well-being over time and changes in personality similarity over time. There is evidence that the psychological characteristics between individuals become more similar over time (Chopik, Kim, \& Smith, 2018; Hoppmann \& Gerstorf, 2009; Neal, Durbin, Gornik, \& Lo, 2017; Schimmack \& Lucas, 2010; Watson et al., 2004). Increasing levels of similarity between couple members often translate to better health, well-being, and interpersonal outcomes (Hoppmann, Gerstorf, \& Luszcz, 2008; Saxbe et al., 2016). Although Big Five personality traits have been the subject of much attention in work on couple similarity, no study to our knowledge explicitly examines correlated changes in Big Five characteristics within couples over time. The antecedents and consequences of these changes in similarity over time may shed insight into how important personality similarity is for couples' well-being. In the current study, personality similarity was negligibly associated with relationship length $(r=-.06)$ and relationship length rarely moderated personalitywell-being associations. However, all of the analyses conducted in the current report are cross-sectional, which leaves open a number of interpretations of the effects regarding relationship length. Future studies should follow couples longitudinally to examine how changes in similarity might be related to global and experiential measures of well-being over time. Further, regarding the limitations on generalizability, the results of the current study can only be generalized to predominantly white, middle-aged couples from the United States. We do not believe any other restrictions or circumstances (e.g., measures, sample size) would otherwise limit the current study's generalizability.

Measurement of study constructs.-A major limitation of the current study also involves the measurement of our constructs of interest, in particular Big Five personality traits and experienced well-being. First, the personality questionnaire used was a short-form version of a longer personality questionnaire, which might have limited the validity and reliability of our measurement of Big Five personality traits. Thus, it is possible that the lower reliability might have led to the underestimation of similarity effects on well-being. Although it is worth noting that our results mostly converged with other studies that utilized measures of varying lengths (e.g., Dyrenforth et al., 2010; Furler et al., 2013; Hudson \& Fraley, 2014; Weidmann et al., 2017), additional studies examining similarity within couples using more reliable measures of personality traits are needed.

Second, we used a modified form of the Day Reconstruction Method. Instead of having individuals retrospectively report on their well-being across multiple days or episodes, our method asked people to give a summary account of only the previous day. Although a single day's worth of information might be highly informative (Lucas et al., 2018) and the inclusion of additional days may not add much more information over-and-above global measures (Finnigan \& Vazire, 2017), an ideal study would have assessments of well-being across multiple days and across different reference periods (e.g., recalling well-being in situations throughout multiple previous days and reporting well-being in situations as they occur). Future research should include a diversity of well-being assessments to evaluate the substantive contribution they make toward our understanding of an individual's well-being. 
Although including a diverse set of well-being measures is an important consideration for future research, oftentimes researchers must make practical decisions about which measures they can include at the expense of participant burden. These concerns should also be weighed in light of the quality of the information that researchers can glean from experiential measures of well-being. It appears that global and evaluative measures of wellbeing appear to have several similarities, including reliability (although global measures might be better), convergent validity, stability over time, developmental changes, and factor structures (Hudson et al., in press; Hudson, Lucas, \& Donnellan, 2016; Hudson, Lucas, \& Donnellan, 2017; Lucas et al., 2018; Newton, Pladevall-Guyer, Gonzalez, \& Smith, 2016)

There are some scenarios in which experiential measures of well-being may be more useful than global evaluative measures, such as whether particular aspects of a particular situation might affect people's emotional experience (e.g., who is in close proximity to a participant; what activity are they engaged in). However, to date, there is little evidence to suggest that global evaluative measures of well-being are more sensitive to contextual influences, as critics of such measures would argue (Schimmack \& Oishi, 2005; Schwarz \& Strack, 1999; Yap et al., 2017). Indeed, although there appears to be overlap between ESM and DRM descriptions of the same day (Bylsma et al., 2011), it is possible that DRM assessments may also be susceptible to response biases, whether they be incidental situational characteristics affecting the recall experience or memory biases more generally (Hudson et al., in press; Robinson \& Clore, 2002). To date, there have not been many comprehensive examinations comparing ESM-type measures and the DRM and whether the DRM might be susceptible to such influences. We present this information not to make an ultimate judgment on the utility of global and experiential measures of well-being, but to merely suggest that researchers examine the type and amount of information that can be gleaned from their respective uses. Knowing more about what experiential measures do and do not provide will guide future researchers' decisions about whether to include more onerous assessments of well-being, like ESM-type methods and the DRM.

Mechanisms linking personality to well-being.-Finally, still left unanswered is the question of why actor, partner, and similarity in personality affect well-being and how these processes might differ across well-being measures. Almost no studies examining personality -well-being associations in the context of close relationships test the mechanisms that link the two across partners. There are a number of different ways that having a partner with certain traits (or similar traits to individuals) might enhance well-being, whether it be through increasing support in interpersonal situations (Hill, Weston, \& Jackson, 2018), selfefficacy in caregiving interactions (Löckenhoff, Duberstein, Friedman, \& Costa, 2011), positive impressions during conflicts (K. S. Wilson, DeRue, Matta, Howe, \& Conlon, 2016), or responsiveness (S. Wilson \& Durbin, 2012). An important step for future research is to formally examine the individual and relationship characteristics and behaviors that link personality to global and experiential well-being in the context of close relationships.

\section{Conclusion}

The current study examined actor, partner, and similarity effects of personality on global and experiential measures of well-being. Among actor effects, conscientiousness, agreeableness, 
extraversion, and neuroticism were among the most robust predictors of well-being. Among partner effects, conscientiousness and neuroticism were among the most robust predictors of well-being. Similarity effects were consistent with some previous research (Dyrenforth et al., 2010); specifically, couples with greater similarity reported higher well-being, although the effect sizes were generally small and occasionally not significant. The magnitude of the results was generally consistent across global and experiential measures of well-being. The results from the present study constitute a replication of previous results on spousal similarity and extend these results to reveal that personality—well-being associations are consistent across different operationalizations of well-being. Future research can explore different ways of indexing similarity, model changes in personality similarity over time, and uncover the mechanisms linking personality to well-being in the context of close relationships.

\section{Supplementary Material}

Refer to Web version on PubMed Central for supplementary material.

\section{Acknowledgments}

Research reported in this publication was supported by the National Institute of Aging of the National Institute of Health under Award Numbers P01AG029409 and 1R03AG054705-01A1. The content is solely the responsibility of the authors and does not necessarily represent the official views of the National Institutes of Health. Portions of this research were presented at the 2017 IARR Mini-Conference on Interdependence, Interactions, and Relationships in Syracuse, NY.

\section{References}

Anderson C, Keltner D, \& John OP (2003). Emotional convergence between people over time. Journal of Personality and Social Psychology, 84(5), 1054-1068. doi:10.1037/0022-3514.84.5.1054 [PubMed: 12757148]

Anusic I, Lucas RE, \& Donnellan MB (2017). The Validity of the Day Reconstruction Method in the German Socio-economic Panel Study. Social Indicators Research, 130(1), 213-232. doi:10.1007/ s11205-015-1172-6 [PubMed: 30532344]

Anusic I, \& Schimmack U (2016). Stability and change of personality traits, self-esteem, and wellbeing: Introducing the meta-analytic stability and change model of retest correlations. Journal of Personality and Social Psychology, 110(5), 766-781. doi:10.1037/pspp0000066 [PubMed: 26619304]

Arrindell WA, \& Luteijn F (2000). Similarity between intimate partners for personality traits as related to individual levels of satisfaction with life. Personality and Individual Differences, 28(4), 629-637. doi:10.1016/S0191-8869(99)00125-7

Barelds DPH (2005). Self and partner personality in intimate relationships. European Journal of Personality, 19(6), 501-518. doi:10.1002/per.549

Barford KA, \& Smillie LD (2016). Openness and other Big Five traits in relation to dispositional mixed emotions. Personality and Individual Differences, 102, 118-122. doi:10.1016/j.paid. 2016.07.002

Benjamin DJ, Berger JO, Johannesson M, Nosek BA, Wagenmakers EJ, Berk R, ... Johnson VE. (2018). Redefine statistical significance. Nature Human Behaviour, 2(1), 6-10. doi:10.1038/ s41562-017-0189-z

Birditt KS, Newton NJ, Cranford JA, \& Ryan LH (2016). Stress and Negative Relationship Quality among Older Couples: Implications for Blood Pressure. The Journals of Gerontology: Series B, 71(5), 775-785. doi:10.1093/geronb/gbv023 
Bolger N, \& Schilling EA (1991). Personality and the problems of everyday life: The role of neuroticism in exposure and reactivity to daily stressors. Journal of Personality, 59(3), 355-386. [PubMed: 1960637]

Botwin MD, Buss DM, \& Shackelford TK (1997). Personality and Mate Preferences: Five Factors In Mate Selection and Marital Satisfaction. Journal of Personality, 65(1), 107-136. doi:10.1111/j. 1467-6494.1997.tb00531.x [PubMed: 9143146]

Buyukcan A, Campbell L, Finkenauer C, Karremans JC, \& Kappen G (2017). Ideal standards, acceptance, and relationship satisfaction: latitudes of differential effects. Frontiers in Psychology.

Bylsma LM, Croon MA, Vingerhoets AJJM, \& Rottenberg J (2011). When and for whom does crying improve mood? A daily diary study of 1004 crying episodes. Journal of Research in Personality, 45(4), 385-392. doi:10.1016/j.jrp.2011.04.007

Byrne D (1961). Interpersonal attraction and attitude similarity. The Journal of Abnormal and Social Psychology, 62(3), 713. doi:10.1037/h0044721 [PubMed: 13875334]

Byrne D, \& Nelson D (1965). Attraction as a linear function of proportion of positive reinforcements. Journal of Personality and Social Psychology, 1(6), 659. doi:10.1037/h0022073 [PubMed: 14300244]

Campbell A, Converse PE, \& Rodgers W (1976). The quality of American life: Perceptions, evaluations, and satisfactions. New York, NY: Russell Sage Foundation.

Cantril H (1965). The pattern of human concerns. New Brunswich, NJ: Rutgers University Press.

Cheung F, \& Lucas RE (2014). Assessing the validity of single-item life satisfaction measures: results from three large samples. Quality of Life Research, 23(10), 2809-2818. doi:10.1007/ s11136-014-0726-4 [PubMed: 24890827]

Chopik WJ, Kim ES, \& Smith J (2018). An examination of dyadic changes in optimism and physical health over time. Health Psychology.

Chopik WJ, \& Motyl M (2016). Ideological Fit Enhances Interpersonal Orientations. Social Psychological and Personality Science, 7(8), 759-768. doi:10.1177/1948550616658096

Chopik WJ, Newton NJ, Ryan LH, Kashdan TB, \& Jarden AJ (2018). Gratitude across the life span: Age differences and links to subjective well-being. Journal of Positive Psychology.

Chopik WJ, Wardecker BM, \& Edelstein RS (2014). Be Mine: Attachment avoidance predicts perceptions of relationship functioning on Valentine's Day. Personality and Individual Differences, $63,47-52$.

DeNeve KM, \& Cooper H (1998). The happy personality: a meta-analysis of 137 personality traits and subjective well-being. Psychol Bull, 124(2), 197-229. [PubMed: 9747186]

Diener E (1984). Subjective well-being. Psychological bulletin, 95, 542-575. [PubMed: 6399758]

Diener E, \& Chan MY (2011). Happy people live longer: Subjective well-being contributes to health and longevity. Applied Psychology: Health and Well-Being, 3(1), 1-43.

Diener E, Emmons RA, Larsen RJ, \& Griffin S (1985). The satisfaction with life scale. Journal of Personality Assessment, 49(1), 71-75. [PubMed: 16367493]

Diener E, Lucas RE, \& Oishi S (2018). Advances and Open Questions in the Science of Subjective Well-Being. Collabra: Psychology, 4(1), 15. [PubMed: 30637366]

Diener E, Suh EM, Lucas RE, \& Smith HE (1999). Subjective well-being: Three decades of progress. Psychological bulletin, 125, 276-302.

Diener E, Wirtz D, Tov W, Kim-Prieto C, Choi D. w., Oishi S, \& Biswas-Diener R (2010). New Wellbeing Measures: Short Scales to Assess Flourishing and Positive and Negative Feelings. Social Indicators Research, 97(2), 143-156. doi:10.1007/s11205-009-9493-y

Dockray S, Grant N, Stone AA, Kahneman D, Wardle J, \& Steptoe A (2010). A comparison of affect ratings obtained with ecological momentary assessment and the day reconstruction method. Social Indicators Research, 99(2), 269-283. [PubMed: 21113328]

Donnellan MB, Assad KK, Robins RW, \& Conger RD (2007). Do negative interactions mediate the effects of Negative Emotionality, Communal Positive Emotionality, and Constraint on relationship satisfaction? Journal of Social and Personal Relationships, 24(4), 557-573. doi: $10.1177 / 0265407507079249$ 
Donnellan MB, \& Lucas RE (2008). Age differences in the big five across the life span: Evidence from two national samples. Psychology and Aging, 23(3), 558-566. doi:10.1037/a0012897 [PubMed: 18808245]

Donnellan MB, Oswald FL, Baird BM, \& Lucas RE (2006). The mini-IPIP scales: tiny-yet-effective measures of the Big Five factors of personality. Psychol Assess, 18(2), 192-203. [PubMed: 16768595]

Dyrenforth PS, Kashy DA, Donnellan MB, \& Lucas RE (2010). Predicting relationship and life satisfaction from personality in nationally representative samples from three countries: the relative importance of actor, partner, and similarity effects. J Pers Soc Psychol, 99(4), 690-702. doi: 10.1037/a0020385 [PubMed: 20718544]

Finkel EJ, Eastwick PW, Karney BR, Reis HT, \& Sprecher S (2012). Online dating: A critical analysis from the perspective of psychological science. Psychological Science in the Public Interest, 13(1), 3-66. doi:10.1177/1529100612436522 [PubMed: 26173279]

Finnigan KM, \& Vazire S (2017). The Incremental Validity of Average State Self-Reports Over Global Self-Reports of Personality. Journal of Personality and Social Psychology, No Pagination Specified-No Pagination Specified. doi:10.1037/pspp0000136

Fredrickson BL (2001). The role of positive emotions in positive psychology: The broaden-and-build theory of positive emotions. American Psychologist, 56(3), 218-226. doi:10.1037/0003-066x. 56.3.218 [PubMed: 11315248]

Furler K, Gomez V, \& Grob A (2013). Personality similarity and life satisfaction in couples. Journal of Research in Personality, 47(4), 369-375. doi:10.1016/j.jrp.2013.03.002

Furr MR (2008). A Framework for Profile Similarity: Integrating Similarity, Normativeness, and Distinctiveness. Journal of Personality, 76(5), 1267-1316. doi:doi:10.1111/j. 1467-6494.2008.00521.x [PubMed: 18705644]

Gattis KS, Berns S, Simpson LE, \& Christensen A (2004). Birds of a Feather or Strange Birds? Ties Among Personality Dimensions, Similarity, and Marital Quality. Journal of Family Psychology, 18(4), 564-574. doi:10.1037/0893-3200.18.4.564 [PubMed: 15598162]

Gaunt R (2006). Couple Similarity and Marital Satisfaction: Are Similar Spouses Happier? Journal of Personality, 74(5), 1401-1420. doi:10.1111/j.1467-6494.2006.00414.x [PubMed: 16958707]

Gerlitz Y, \& Schupp J (2005). Assessment of big five personality characteristics in the SOEP In German Institute of Economic Research (Research Notes 4). Berlin: DIW.

Gonzaga GC, Campos B, \& Bradbury T (2007). Similarity, convergence, and relationship satisfaction in dating and married couples. Journal of Personality and Social Psychology, 93(1), 34-48. doi: 10.1037/0022-3514.93.1.34 [PubMed: 17605587]

Gosling SD, Rentfrow PJ, \& Swann WB Jr (2003). A very brief measure of the Big-Five personality domains. Journal of Research in Personality, 37(6), 504-528. doi:10.1016/ S0092-6566(03)00046-1

Gray JA (1987). The neuropsychology of emotion and personality In Stahl SM \& Iversen SD (Eds.), Cognitive neurochemistry (pp. 171-190). Oxford: Oxford University Press.

Griffin D, \& Gonzalez R (1995). Correlational analysis of dyad-level data in the exchangeable case. Psychological bulletin, 118(3), 430-439.

Gustavson K, Røysamb E, Borren I, Torvik FA, \& Karevold E (2016). Life satisfaction in close relationships: Findings from a longitudinal study. Journal of Happiness Studies, 17(3), 1293-1311.

Headey B, Muffels R, \& Wagner GG (2010). Long-running German panel survey shows that personal and economic choices, not just genes, matter for happiness. Proceedings of the National Academy of Sciences, 107(42), 17922-17926. doi:10.1073/pnas.1008612107

Heller D, Watson D, \& Ilies R (2004). The Role of Person Versus Situation in Life Satisfaction: A Critical Examination. Psychological bulletin, 130(4), 574-600. doi:10.1037/0033-2909.130.4.574 [PubMed: 15250814]

Hill PL, Weston SJ, \& Jackson JJ (2018). The co-development of perceived support and the Big Five in middle and older adulthood. International journal of behavioral development, 42(1), 26-33. doi: $10.1177 / 0165025417690262$ 
Holland AS, \& Roisman GI (2008). Big Five personality traits and relationship quality: Self-reported, observational, and physiological evidence. Journal of Social and Personal Relationships, 25(5), 811-829.

Hoppmann CA, \& Gerstorf D (2009). Spousal interrelations in old age-A mini-review. Gerontology, 55(4), 449-459. doi:10.1159/000211948 [PubMed: 19346740]

Hoppmann CA, Gerstorf D, \& Luszcz M (2008). Spousal social activity trajectories in the Australian Longitudinal Study of Ageing in the context of cognitive, physical, and affective resources. The Journals of Gerontology: Series B: Psychological Sciences and Social Sciences, 63B(1), P41-P50. doi:10.1093/geronb/63.1.P41

Hudson NW, Anusic I, Lucas RE, \& Donnellan MB (in press). Comparing the reliability and validity of global self-report measures of subjective well-being with experiential day reconstruction measures. Assessment.

Hudson NW, \& Fraley RC (2014). Partner similarity matters for the insecure: Attachment orientations moderate the association between similarity in partners' personality traits and relationship satisfaction. Journal of Research in Personality, 53, 112-123. doi:10.1016/j.jrp.2014.09.004

Hudson NW, Lucas RE, \& Donnellan MB (2016). Getting older, feeling less? A cross-sectional and longitudinal investigation of developmental patterns in experiential well-being. Psychol Aging, 31(8), 847-861. doi:10.1037/pag0000138 [PubMed: 27929340]

Hudson NW, Lucas RE, \& Donnellan MB (2017). Day-To-Day Affect is Surprisingly Stable:A 2-Year Longitudinal Study of Well-Being. Social Psychological and Personality Science, 8(1), 45-54. doi: 10.1177/1948550616662129 [PubMed: 29238453]

Humbad MN, Donnellan MB, Iacono WG, McGue M, \& Burt SA (2010). Is spousal similarity for personality a matter of convergence or selection? Personality and Individual Differences, 49(7), 827-830. doi:10.1016/j.paid.2010.07.010 [PubMed: 21116446]

Humbad MN, Donnellan MB, Iacono WG, McGue M, \& Burt SA (2013). Quantifying the Association between Personality Similarity and Marital Adjustment Using Profile Correlations: A Cautionary Tale. Journal of Research in Personality, 47(1), 97-106. doi:10.1016/j.jrp.2012.09.007 [PubMed: 23459440]

John OP, \& Srivastava S (1999). The Big Five trait taxonomy: History, measurement, and theoretical perspectives. In Pervin LA \& John OP (Eds.), Handbook of personality: Theory and research (pp. 102-138).

Kahneman D, Krueger AB, Schkade D, Schwarz N, \& Stone AA (2006). Would You Be Happier If You Were Richer? A Focusing Illusion. Science, 312(5782), 1908-1910. doi:10.1126/science. 1129688 [PubMed: 16809528]

Kahneman D, Krueger AB, Schkade DA, Schwarz N, \& Stone AA (2004). A survey method for characterizing daily life experience: The Day Reconstruction Method. Science, 306(5702), 17761780. doi:10.1126/science.1103572 [PubMed: 15576620]

Kenny DA, Kashy DA, \& Cook WL (2006). Dyadic data analysis. New York: Guilford Press.

Kessler RC, Andrews G, Colpe LJ, Hiripi E, Mroczek DK, Normand SL, ... Zaslavsky AM. (2002). Short screening scales to monitor population prevalences and trends in non-specific psychological distress. Psychol Med, 32(6), 959-976. [PubMed: 12214795]

Keyes CLM (2002). The Mental Health Continuum: From Languishing to Flourishing in Life. Journal of health and social behavior, 43(2), 207-222. doi:10.2307/3090197 [PubMed: 12096700]

Larsen JT, Coles NA, \& Jordan DK (2017). Varieties of mixed emotional experience. Current Opinion in Behavioral Sciences, 15, 72-76. doi:10.1016/j.cobeha.2017.05.021

Larsen RJ, \& Ketelaar T (1991). Personality and susceptibility to positive and negative emotional states. Journal of Personality and Social Psychology, 61(1), 132. [PubMed: 1890584]

Löckenhoff CE, Duberstein PR, Friedman B, \& Costa PT (2011). Five-Factor Personality Traits and Subjective Health Among Caregivers: The Role of Caregiver Strain and Self-Efficacy. Psychology and Aging, 26(3), 592-604. doi:10.1037/a0022209 [PubMed: 21417534]

Lucas RE (2007). Adaptation and the set-point model of subjective well-being: Does happiness change after major life events? Current directions in psychological science, 16(2), 75-79. doi:10.1111/j. 1467-8721.2007.00479.x 
Lucas RE, Diener E, \& Suh E (1996). Discriminant validity of well-being measures. Journal of Personality and Social Psychology, 71(3), 616. [PubMed: 8831165]

Lucas RE, \& Donnellan MB (2012). Estimating the reliability of single-item life satisfaction measures: Results from four national panel studies. Social Indicators Research, 105(3), 323-331. doi: 10.1007/s11205-011-9783-z [PubMed: 23087538]

Lucas RE, Freedman VA, \& Carr D (2018). Measuring experiential well-being among older adults. Journal of Positive Psychology. Retrieved from https://psyarxiv.com/umgb4

Luo S, Chen H, Yue G, Zhang G, Zhaoyang R, \& Xu D (2008). Predicting Marital Satisfaction From Self, Partner, and Couple Characteristics: Is It Me, You, or Us? Journal of Personality, 76(5), 1231-1266. doi:10.1111/j.1467-6494.2008.00520.x [PubMed: 18665892]

Luo S, \& Klohnen EC (2005). Assortative Mating and Marital Quality in Newlyweds: A CoupleCentered Approach. Journal of Personality and Social Psychology, 88(2), 304-326. doi: 10.1037/0022-3514.88.2.304 [PubMed: 15841861]

Malouff JM, Thorsteinsson EB, Schutte NS, Bhullar N, \& Rooke SE (2010). The Five-Factor Model of personality and relationship satisfaction of intimate partners: A meta-analysis. Journal of Research in Personality, 44(1), 124-127. doi:10.1016/j.jrp.2009.09.004

McCrae RR, Martin TA, Hrebickova M, Urbánek T, Boomsma DI, Willemsen G, \& Costa PT (2008). Personality trait similarity between spouses in four cultures. Journal of Personality, 76(5), $1137-$ 1164. doi:10.1111/j.1467-6494.2008.00517.x [PubMed: 18665894]

Mejía ST, \& Gonzalez R (2017). Couples' Shared Beliefs About Aging and Implications for Future Functional Limitations. The Gerontologist, 57(suppl_2), S149-S159. doi:10.1093/geront/gnx071 [PubMed: 28854612]

Montoya RM, Horton RS, \& Kirchner J (2008). Is actual similarity necessary for attraction? A metaanalysis of actual and perceived similarity. Journal of Social and Personal Relationships, 25(6), 889-922. doi:10.1177/0265407508096700

Mroczek DK, \& Kolarz CM (1998). The effect of age on positive and negative affect: A developmental perspective on happiness. Journal of Personality and Social Psychology, 75(5), 1333-1349. doi: 10.1037/0022-3514.75.5.1333 [PubMed: 9866191]

Neal JW, Durbin CE, Gornik AE, \& Lo SL (2017). Codevelopment of preschoolers' temperament traits and social play networks over an entire school year. Journal of Personality and Social Psychology, 113, 627-640. [PubMed: 28150979]

Newton NJ, Pladevall-Guyer J, Gonzalez R, \& Smith J (2016). Activity engagement and activityrelated experiences: The role of personality. Journals of Gerontology: Social Sciences.

O’Brien E, Ellsworth PC, \& Schwarz N (2012). Today's misery and yesterday's happiness: Differential effects of current life-events on perceptions of past wellbeing. Journal of experimental social psychology, 48(4), 968-972. doi:10.1016/j.jesp.2012.02.018

Orth U (2013). How large are actor and partner effects of personality on relationship satisfaction? The importance of controlling for shared method variance. Personality and Social Psychology Bulletin, 39(10), 1359-1372. doi:10.1177/0146167213492429 [PubMed: 23798373]

Pavot W, Diener E, Colvin CR, \& Sandvik E (1991). Further validation of the Satisfaction with Life Scale: evidence for the cross-method convergence of well-being measures. J Pers Assess, 57(1), 149-161. doi:10.1207/s15327752jpa5701_17 [PubMed: 1920028]

Rammstedt B, \& John OP (2007). Measuring personality in one minute or less: A 10-item short version of the Big Five Inventory in English and German. Journal of Research in Personality, 41, 203-212.

Robins RW, Caspi A, \& Moffitt TE (2000). Two personalities, one relationship: Both partners' personality traits shape the quality of their relationship. Journal of Personality and Social Psychology, 79(2), 251-259. doi:10.1037/0022-3514.79.2.251 [PubMed: 10948978]

Robinson MD, \& Clore GL (2002). Belief and feeling: Evidence for an accessibility model of emotional self-report. Psychological bulletin, 128, 934-960. [PubMed: 12405138]

Rogers KH, Wood D, \& Furr RM (2018). Assessment of similarity and self-other agreement in dyadic relationships:A guide to best practices. Journal of Social and Personal Relationships, 35(1), 112134. doi:10.1177/0265407517712615

$J$ Res Pers. Author manuscript; available in PMC 2020 February 01. 
Saxbe DE, Edelstein RS, Lyden HM, Wardecker BM, Chopik WJ, \& Moors AC (2016). Fathers' Decline In Testosterone And Synchrony With Partner Testosterone During Pregnancy Predicts Greater Postpartum Relationship Investment. Hormones and Behavior.

Schimmack U, \& Lucas RE (2010). Environmental influences on well-being: A dyadic latent panel analysis of spousal similarity. Social Indicators Research, 98(1), 1-21.

Schimmack U, \& Oishi S (2005). The influence of chronically and temporarily accessible information on life satisfaction judgments. Journal of Personality and Social Psychology, 89(3), 395. [PubMed: $16248721]$

Schönbrodt FD (2016). RSA: An R package for response surface analysis (version 0.9.10). Retrieved from https://cran.r-project.org/package=RSA

Schwarz N, \& Strack F (1999). Reports of subjective wellbeing: Judgmental processes and their methodological implications In Kahneman D, Diener E, \& Schwarz N (Eds.), Well-being: The foundations of hedonic psychology (pp. 61-84). New York, NY: Russell Sage Foundation.

Scott SB, Sliwinski MJ, Mogle JA, \& Almeida DM (2014). Age, Stress, and Emotional Complexity: Results from Two Studies of Daily Experiences. Psychology and Aging, 29(3), 577-587. doi: 10.1037/a0037282 [PubMed: 25244477]

Seligman ME, \& Csikszentmihalyi M (2000). Positive psychology. An introduction. Am Psychol, 55(1), 5-14. [PubMed: 11392865]

Shiffman S, Stone AA, \& Hufford MR (2008). Ecological momentary assessment. Annu. Rev. Clin. Psychol, 4, 1-32. [PubMed: 18509902]

Srivastava S, John OP, Gosling SD, \& Potter J (2003). Development of personality in early and middle adulthood: Set like plaster or persistent change? Journal of Personality and Social Psychology, 84(5), 1041-1053. doi:10.1037/0022-3514.84.5.1041 [PubMed: 12757147]

Steel P, Schmidt J, \& Shultz J (2008). Refining the relationship between personality and subjective well-being. Psychological bulletin, 134(1), 138. [PubMed: 18193998]

Suls J, Green P, \& Hillis S (1998). Emotional reactivity to everyday problems, affective inertia, and neuroticism. Personality and Social Psychology Bulletin, 24(2), 127-136.

Tidwell ND, Eastwick PW, \& Finkel EJ (2013). Perceived, not actual, similarity predicts initial attraction in a live romantic context: Evidence from the speed-dating paradigm. Personal Relationships, 20(2), 199-215.

van Scheppingen MA, Chopik WJ, Bleidorn W, \& Denissen JJA (2018). Longitudinal actor, partner, and similarity effects of personality on well-being. Journal of Personality and Social Psychology.

Watson D, Beer A, \& McDade-Montez E (2014). The Role of Active Assortment in Spousal Similarity. Journal of Personality, 82(2), 116-129. doi:10.1111/jopy.12039 [PubMed: 23551151]

Watson D, \& Clark LA (1984). Negative affectivity: the disposition to experience aversive emotional states. Psychological bulletin, 96(3), 465. [PubMed: 6393179]

Watson D, Clark LA, \& Tellegen A (1988). Development and validation of brief measures of positive and negative affect: the PANAS scales. J Pers Soc Psychol, 54(6), 1063-1070. [PubMed: 3397865]

Watson D, Klohnen EC, Casillas A, Nus Simms E, Haig J, \& Berry DS (2004). Match Makers and Deal Breakers: Analyses of Assortative Mating in Newlywed Couples. Journal of Personality, 72(5), 1029-1068. doi:10.1111/j.0022-3506.2004.00289.x [PubMed: 15335336]

Weidmann R, Schönbrodt FD, Ledermann T, \& Grob A (2017). Concurrent and longitudinal dyadic polynomial regression analyses of Big Five traits and relationship satisfaction: Does similarity matter? Journal of Research in Personality, 70, 6-15.

Wilson KS, DeRue DS, Matta FK, Howe M, \& Conlon DE (2016). Personality similarity in negotiations: Testing the dyadic effects of similarity in interpersonal traits and the use of emotional displays on negotiation outcomes. J Appl Psychol, 101(10), 1405-1421. doi:10.1037/ ap10000132 [PubMed: 27336910]

Wilson S, \& Durbin CE (2012). Dyadic parent-child interaction during early childhood: contributions of parental and child personality traits. J Pers, 80(5), 1313-1338. doi:10.1111/j. 1467-6494.2012.00789.x [PubMed: 22433002]

Wrosch C, Jobin J, \& Scheier MF (2016). Do the Emotional Benefits of Optimism Vary Across Older Adulthood? A Life Span Perspective. Journal of Personality, n/a-n/a. doi:10.1111/jopy.12247 
Yap SCY, Wortman J, Anusic I, Baker SG, Scherer LD, Donnellan MB, \& Lucas RE (2017). The effect of mood on judgments of subjective well-being: Nine tests of the judgment model. Journal of Personality and Social Psychology, 113(6), 939-961. doi:10.1037/pspp0000115 [PubMed: 27936835]

Youyou W, Stillwell D, Schwartz HA, \& Kosinski M (2017). Birds of a Feather Do Flock Together: Behavior-Based Personality-Assessment Method Reveals Personality Similarity Among Couples and Friends. Psychological science, 28(3), 276-284. [PubMed: 28059682]

Zhou Y, Wang K, Chen S, Zhang J, \& Zhou M (2017). The Actor, Partner, Similarity Effects of Personality, and Interactions with Gender and Relationship Duration among Chinese Emerging Adults. Frontiers in Psychology, 8, 1698. doi:10.3389/fpsyg.2017.01698 [PubMed: 29033878] 


\section{Highlights}

We examined actor, partner, and similarity effects of personality on well-being.

Actor $\mathrm{C}, \mathrm{A}, \mathrm{E}$, and $\mathrm{N}$ were the most robust predictors of individual well-being.

Partner $\mathrm{C}$ and $\mathrm{N}$ were the most robust predictors of individual well-being.

Results are discussed in the context of experiential well-being and similarity. 


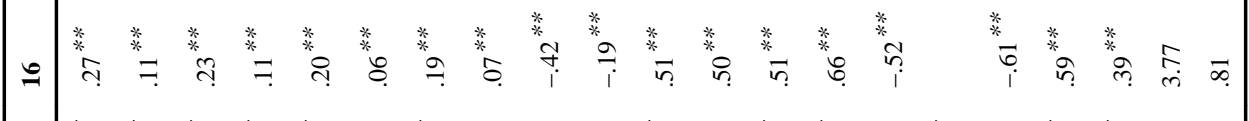

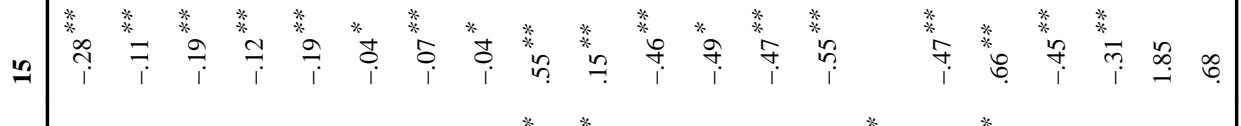

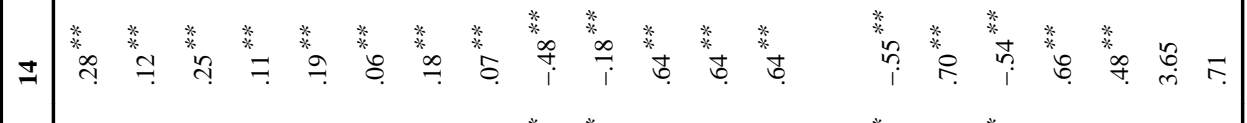

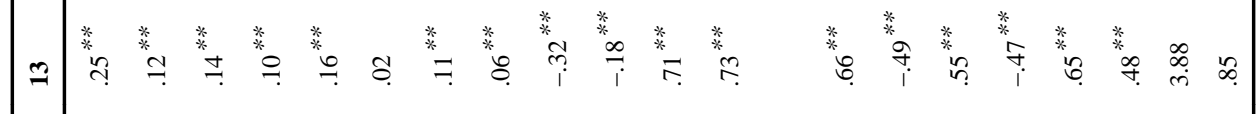

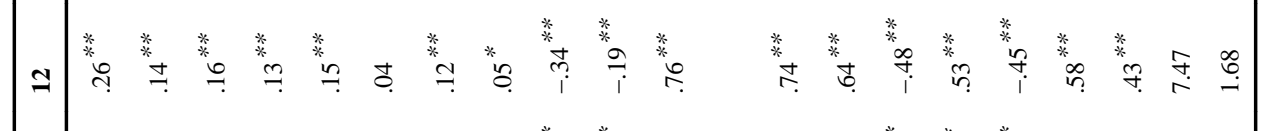

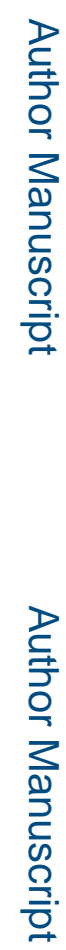

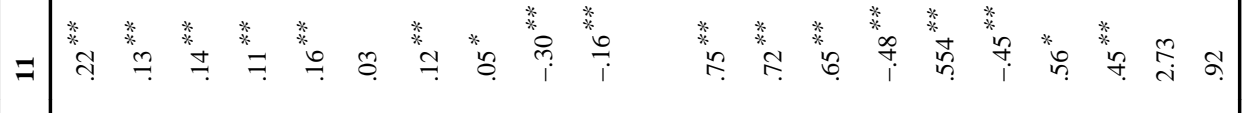

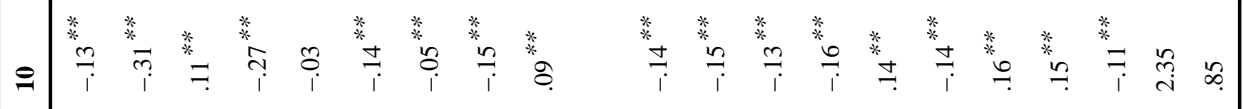

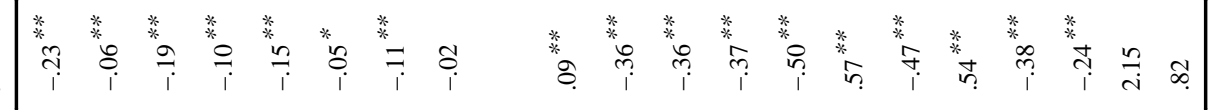

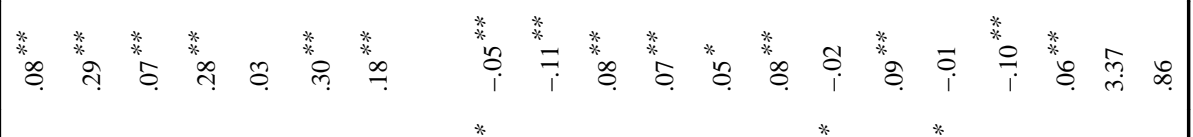

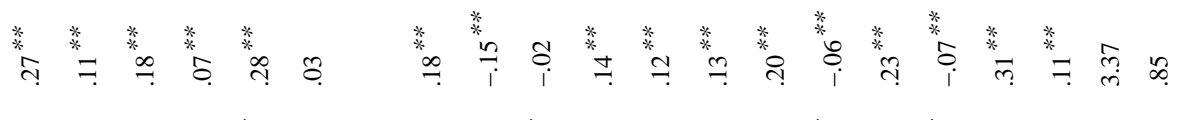

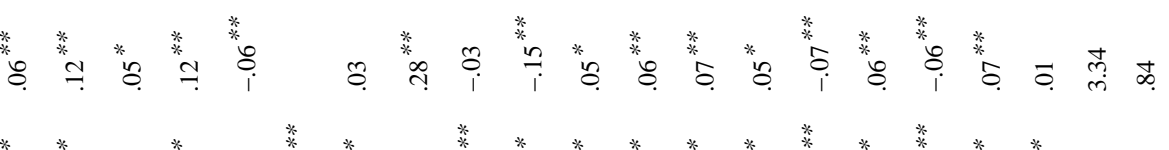

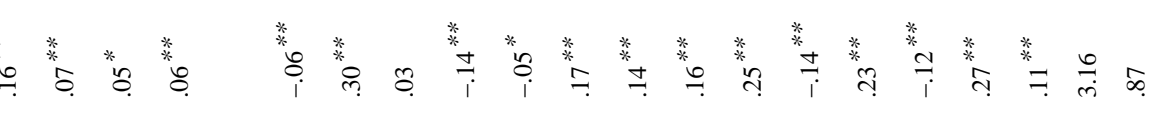
$\exists$ *

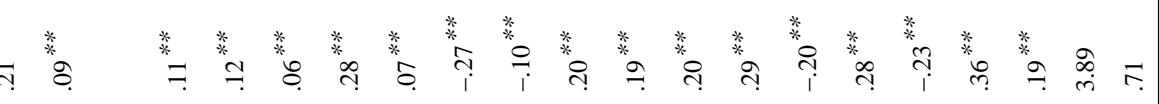
* * * * * * * * * *

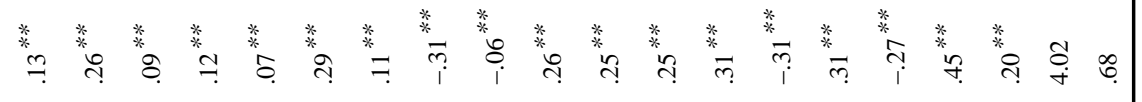

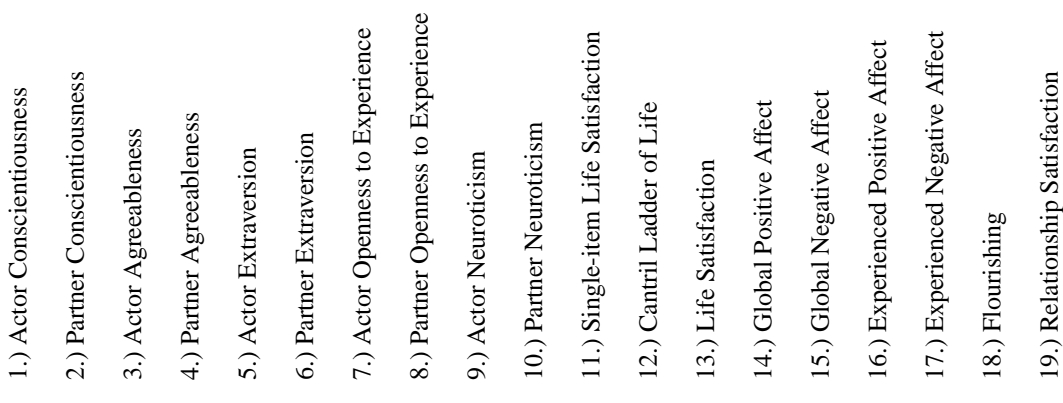
$\sum$ क 


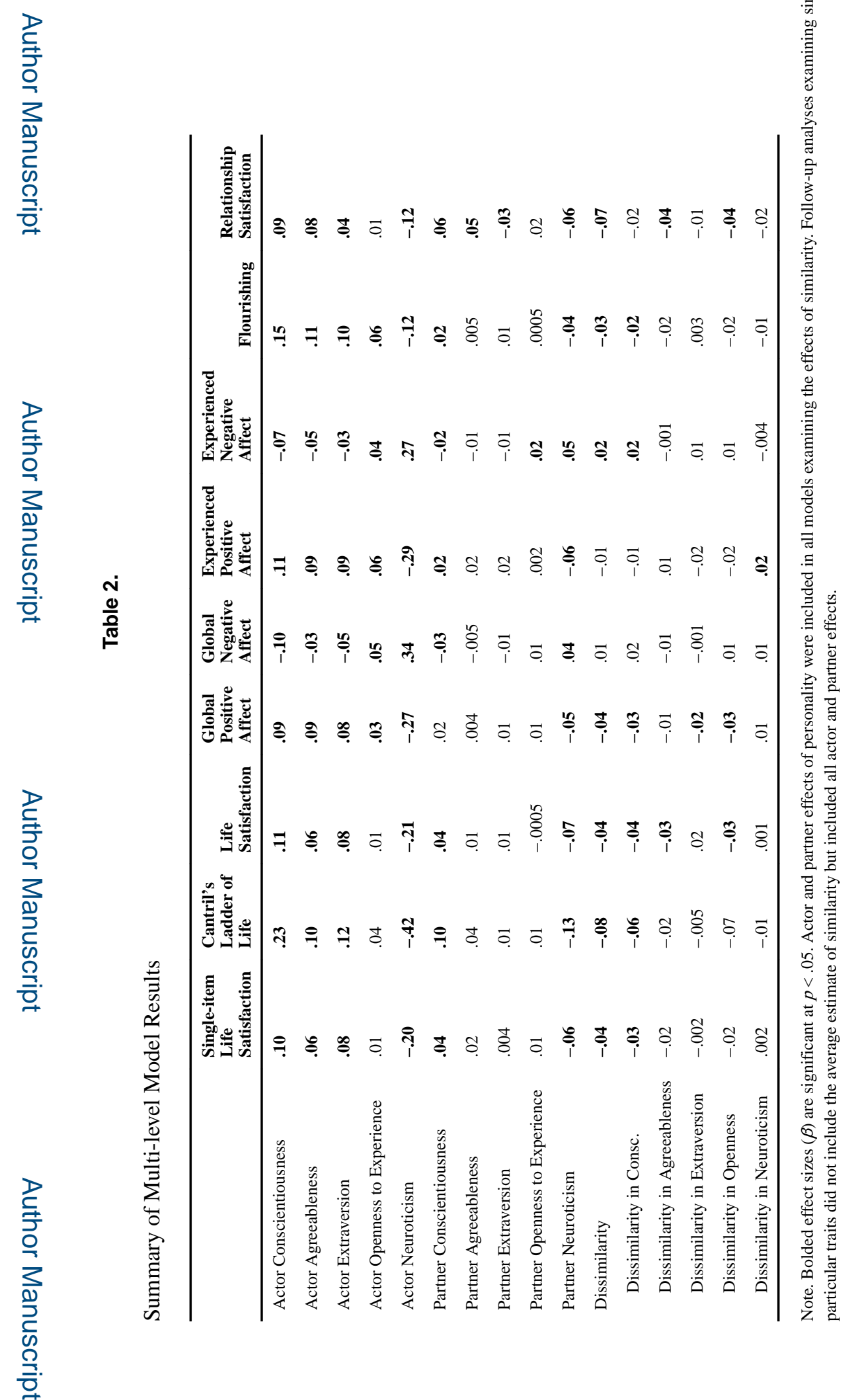

$J$ Res Pers. Author manuscript; available in PMC 2020 February 01. 


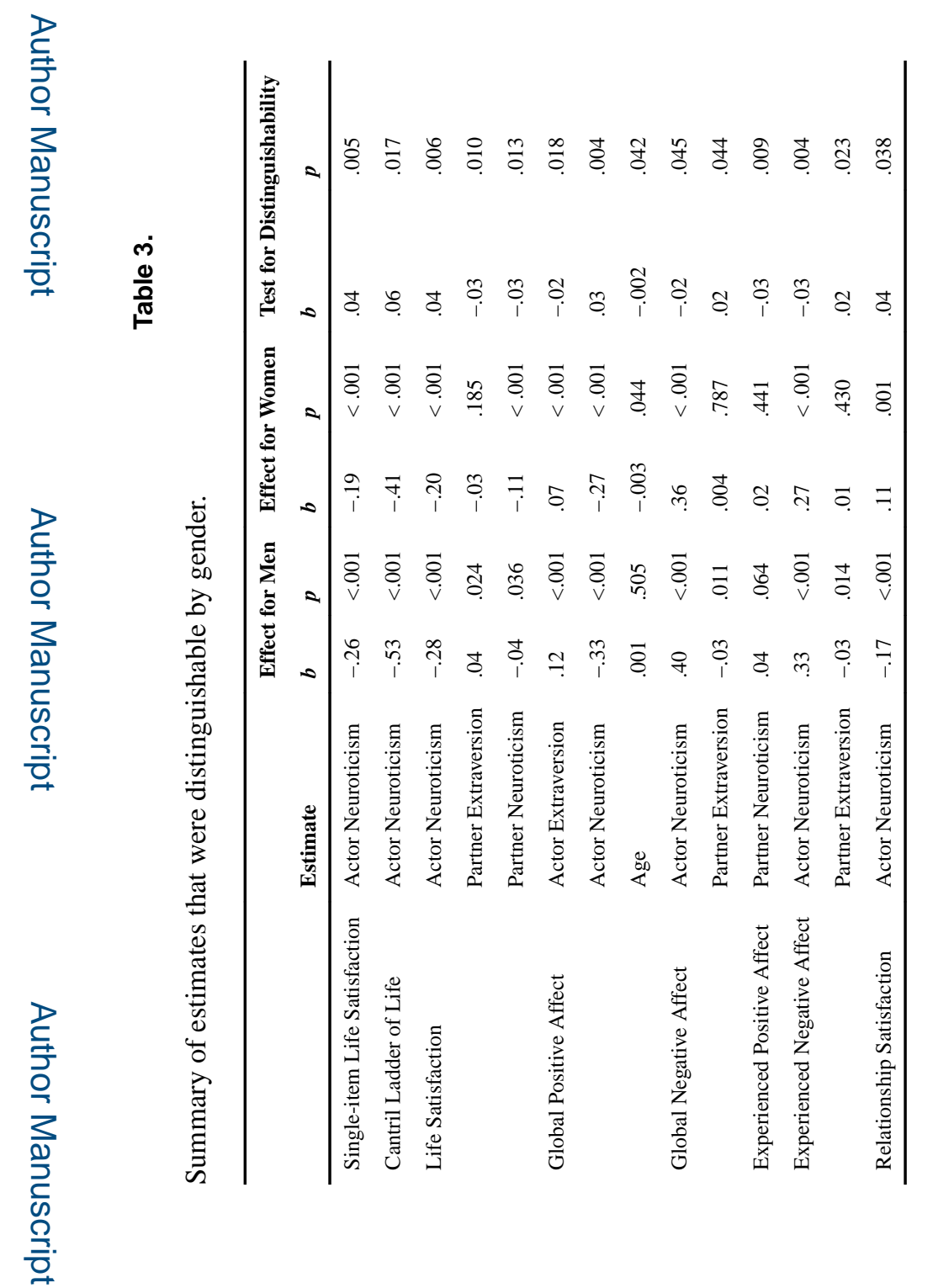




\section{록 \\ }

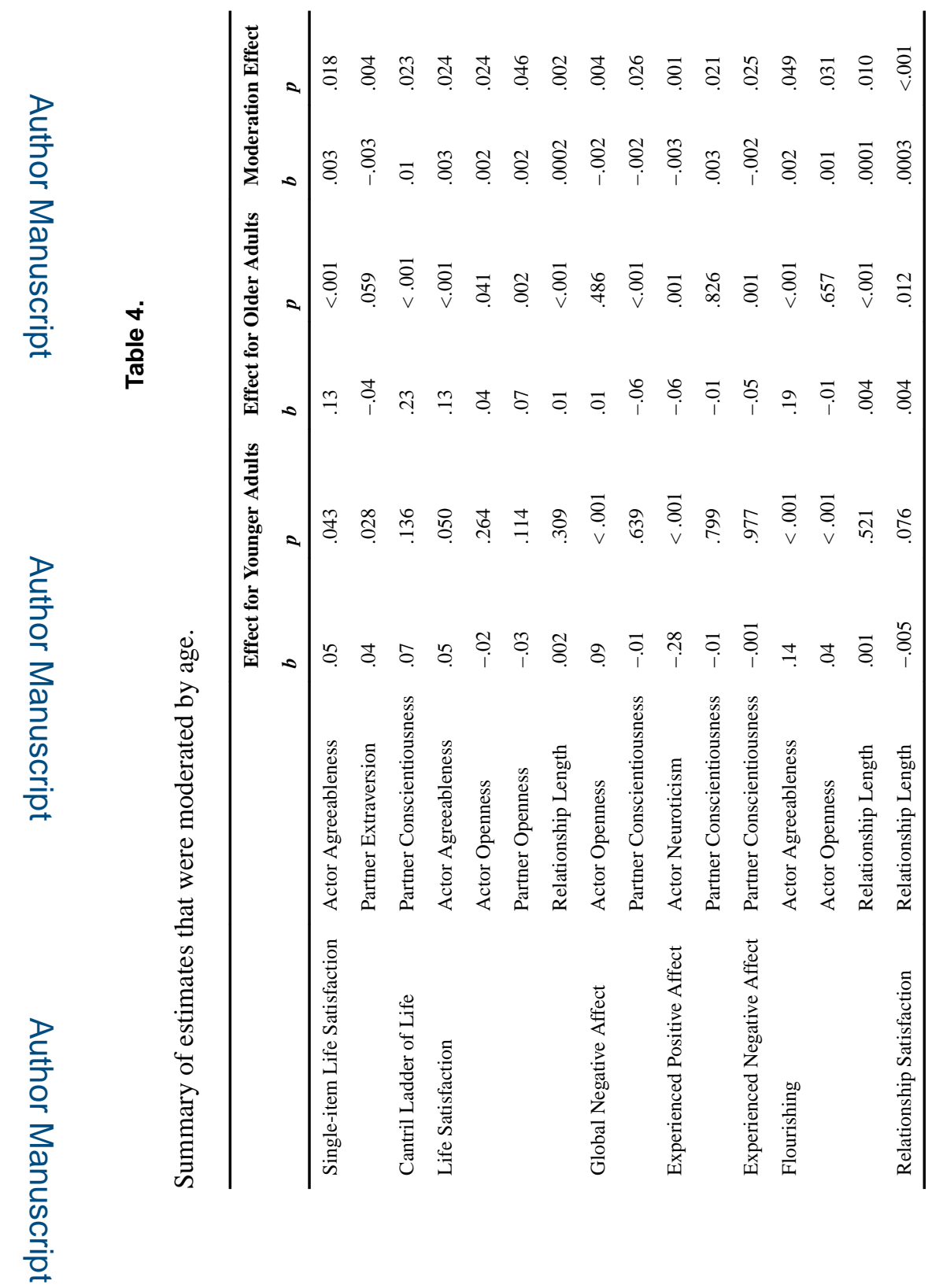

$J$ Res Pers. Author manuscript; available in PMC 2020 February 01 

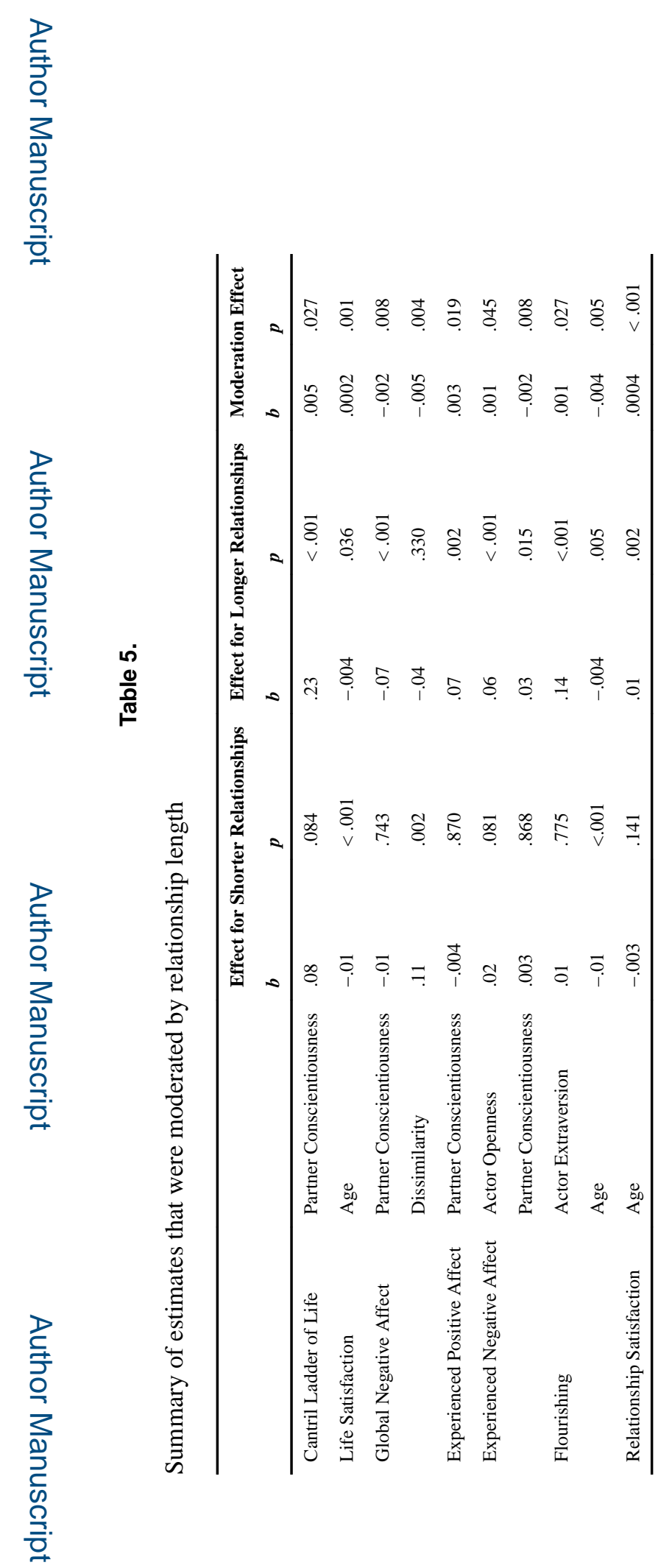

$J$ Res Pers. Author manuscript; available in PMC 2020 February 01. 